\title{
ON THE CHARACTERIZATION OF OUTDOOR CABLES AS DATA COMMUNICATION CHANNELS*
}

Sobhy S. Al-dosouki ${ }^{+}$, Abdul-Fattah I. Abdul-Fattah ${ }^{+}$, Ahmed A.S. Dosouki ${ }^{+}, \mathrm{Samah} \mathrm{H.} \mathrm{Gomaa**}^{\text {** }}$

+ Faculty of Engineering, Port Said University, Egypt

** North Delta Electricity Distribution Company

\begin{abstract}
ASTRACT:
Power Line Communication (PLC) has been considered as attractive media for high speed data transmission, particularly for applications like home networking, Internet, voice and data services. For the use of the Low Voltage networks as high speed data channel the path carrier frequencies within the range up to $30 \mathrm{MHz}$ must be considered. The development of suitable communication systems and the planning of PLC networks require modeling of the transfer characteristics of the mains network in the mentioned frequency range. In this paper the considered PLC channel is North Delta Electricity Distribution Company (NDEDC) Outdoor low voltage cables, the frequency and phase responses of a three-phase power line channel with interconnections are derived. The channel transfer function is obtained and investigated using different cable lengths, and different number of branches under a given loading conditions.

Loading mismatching at different branches is considered. Transfer characteristics of power line channel from distribution transformer to customer pole have been modeled using the chain matrix methodology. Simulation results indicate that there are significant attenuations and distortions as the number of branches, cable length, and load mismatching are increased.
\end{abstract}

KEYWORDS: High frequency band PLC, North Delta Electricity Distribution Company (NDEDC), PLC channel characterization

\section{SUR LA CARACTERISATION DES CABLES EXTERIEURS AS CANAUX DE DONNEES COM-MUNICATION}

\section{RÉSUMÉ}

Power Line Communication (PLC) a été considérés comme des supports attractifs pour la vitesse de transmission de données élevés, en particulier pour des applications comme les réseaux domestiques, Internet, services voix et données. Pour l'utilisation des réseaux basse tension sous forme de données à grande vitesse les fréquences porteuses de canal chemin au sein de la gamme jusqu'à $30 \mathrm{MHz}$ doit être considéré. Le développement de systèmes de communication adaptés et la planification des réseaux PLC nécessitent la modélisation des caractéristiques de transfert du réseau électrique dans la gamme de fréquences mentionnées. Dans cet article, la voie considérée PLC est Nord Delta Electricité Distribution Compagnie (NDEDC) Câbles extérieurs basse tension, la fréquence-réponses et de phase d'un canal de la ligne d'alimentation à trois phases avec des interconnexions sont dérivés. La fonction de transfert de canal est obtenue et étudiée en utilisant différentes longueurs de câble, et le nombre de branches différentes en vertu d'une des conditions de chargement donné.

Chargement désadaptation à différentes branches est considéré. Caractéristiques de transfert du canal de la ligne d'alimentation de transformateur de distribution sur le poteau à la clientèle ont été modélisés en utilisant la chaîne de la méthodologie de la matrice. Les résultats de simulation montrent qu'il existe des atténuations et des distorsions importantes que le nombre de branches, la longueur du câble, et la charge de désadaptation sont augmentés.

MOTS-CLES: Haute bande de fréquence PLC, Nord Delta Electricité Distribution Compagnie (NDEDC), la caractérisation de canaux PLC

\footnotetext{
* Recieved: 6/6/2010, accepted: 29/12/2010 (Review Paper)

** Contact author (samahashim@yahoo.com)
} 


\section{INTRODUCTION:}

Recently, there is a growing interest in the use of power line communication (PLC) to non-urban and lowly populated areas. It is considered to be a viable technology for countries like Egypt where power-line network infrastructure already covers very larger geographical areas. In order to be able to communicate through power-line channel various issues have to be addressed for quality and optimal communication. The power line network differs considerably in topology, structure and physical properties from conventional telecommunication mediums like twisted pair, coaxial or fiber optic cables. Therefore, special communication systems, considering the hostile properties of power line channels, are required (ref. [2], [3], and [4]). For the design of appropriate communication systems and for planning of power line communication networks, models of the transfer characteristics of the low voltage mains network are required. Several approaches for modeling the transfer characteristics of power lines can be found in literature. Most of these models are describing the behaviors of a network by the components using scattering parameter matrices (ref. [1] and [2]) these models generally imply detailed knowledge about the components of the network to determine the elements of the matrices. Communication in PLC is affected by various parameters such as noise, attenuation of the signal and operating frequency. In PLC, the length of the cable, number of branches and transmission frequency contribute to signal attenuation. These factors should be taken into consideration in a PLC system design. In ref. [2] the author used fixed values for cable resistance $(R)$ and conductance $(G)$ when representing the characteristics of the power cable where the values of $R$ and $G$ are frequency dependent values. This paper takes this into consideration. The values of $\mathrm{R}$ and $\mathrm{G}$ are calculated according from equations respective with frequency ranges for PLC (0-30MHZ). The topology of the type of network under discussion is shown in Fig.(1). It consists of Outdoor LV cables (3- phase and neutral) with Sectoral Core Aluminum Conductor XLPE insulated, Steel Tape Armored and PVC Sheathed from the Distribution Transformer (DT) to Customer Pole (CP). The link from DT to CP is up to $10 \mathrm{~m}$ long, $3 * 150+70 \mathrm{~mm}^{2}$, the simulation being based on the technical data specified for outdoor cables used in the Low-Voltage grid of North Delta Electricity Distribution Company (NDEDC) in Mansoura city.

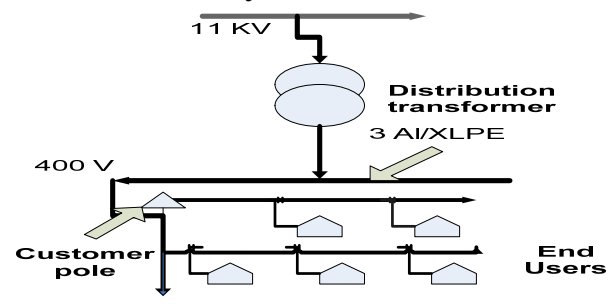

Fig.(1): Topology of LV power-line distribution network

\section{CHAIN MATRIX FOR PLC MODELING:}

Generally, the power line communication channel can be modeled using the chain matrix theory or the ABCD matrix theory. Based on this theory the transfer function of a sample power line channel can be computed. A communication 
channel can be represented as a two port channel as shown in Fig.(2), and can be described using an ABCD matrix. This provides a convenient way for determining the transfer function of the channel [2].

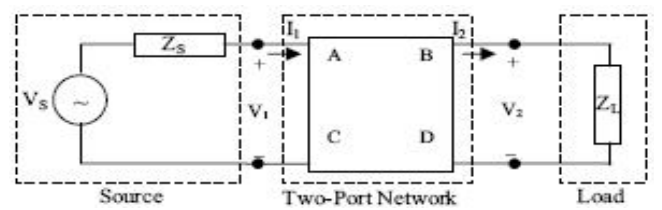

Fig.(2): Two port PLC channel with chain matrix [2].

The PLC channel is represented in terms of its transmission matrix shown in (1):

$\left(\begin{array}{ll}A & B \\ C & D\end{array}\right)=\left(\begin{array}{cc}\cosh (\gamma l) & Z_{C} \sinh (\gamma l) \\ 1 / Z_{C} \sinh (\gamma l) & \cosh (\gamma l)\end{array}\right)$

The parameters A, B, C and D are frequency dependent components which are a function of the characteristic impedance $Z_{C}$ and the propagation coefficient $\gamma$. The characteristic impedance $Z_{C}$, and propagation constant $\gamma$ of the communication channel can be computed from the per-unit length parameters of the cable as shown in eqns.(2),(3).

$$
\gamma=\alpha+j \beta=\sqrt{(R+j w L)(G+j w C)}
$$

where $\gamma$ : Propagation constant.

$\alpha$ : Attenuation constant.

$\beta$ : Phase constant.

$Z_{C}=\frac{R+j w L}{\gamma}=\frac{\gamma}{G+j w C}=\sqrt{\frac{R+j w L}{G+j w C}}$

where: $\mathrm{R}, \mathrm{L}, \mathrm{G}$ and $\mathrm{C}$ are cable resistance, inductance, conductance and capacitance per unit length respectively. The transfer function is the ratio of the output to the input of the channel. It can be represented in terms of transmission matrix element

$$
H=\frac{Z_{L}}{C Z_{L} Z_{S}+D Z_{S}+A Z_{L}+B}
$$

where: $Z_{S}, Z_{L}$ are source and load impedances respectively.

The proposed study investigates power line characteristics which have been realized by focusing on the transfer function of PLC channel for different electrical cable lengths, different number of bridge taps and different loading conditions (appliances connectivity) by using ABCD matrix as it has been used in [2]. Additional phase response is obtained and additional calculations have been done for obtaining the cable parameters $\mathrm{R}, \mathrm{L}, \mathrm{G}$, and $\mathrm{C}$ as frequency dependent parameters and not like [2], where these parameters have been taken as fixed values. This analysis has been supported by simulation of PLC channel with the attenuation in magnitude and phase distortion expected in this channel.

In addition, a multi-branch PLC channel is modeled using MATLAB environment. The simulation is based on the technical data specified for outdoor and indoor cables used in LV grid of the Egyptian North Delta Electricity Distribution Company (NDEDC).

\section{CHAIN MATRIX WITH BRIDGE TAP:}

Power line communication systems do not consist of a simple structure as depicted in Fig.(1). Bridge taps with different cable lengths and cable types usually exists along the power line to form a power line network made of sections. Fig.(3) shows a transmission line with one bridge tap. 
For a power line communication network with several sections, the transfer function for the whole network is still the same as in (4), however, the $A B C D$ matrix for the system differs. The ABCD matrix is determined by utilizing the chain rule which involves multiplying the $\mathrm{ABCD}$ matrices for the different sections of the network to produce the overall $\mathrm{ABCD}$ matrix. The $A B C D$ matrix for a serially connected load Zs and the ABCD matrix for load impedance $Z_{\mathrm{P}}$ connected in parallel are defined in [2], a bridge tap terminated with load impedance $Z_{b}$ can be considered to be equivalent to impedance $Z_{e q}$ calculated as:

$$
Z_{e q}=Z_{c} \frac{Z_{b}+Z_{c} \tanh \left(\gamma_{b r} l_{b}\right)}{Z_{c}+Z_{b} \tanh \left(\gamma_{b r} l_{b}\right)}
$$

where $Z_{c}$ and $\gamma_{b r}$ are the characteristic impedance and the propagation constant of the branch circuit respectively. Consider the power line with one bridge tap connection as shown in Fig.3 which can be replaced by an equivalent network shown in Fig.(4) where $Z_{e q}$ calculated using (5).

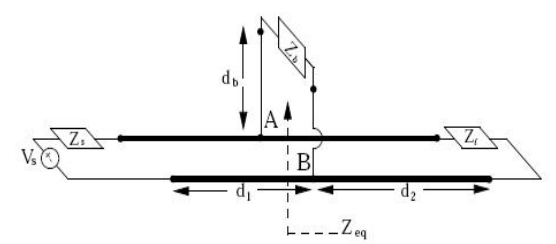

Fig.(3): Power line with one bridge tap [6].

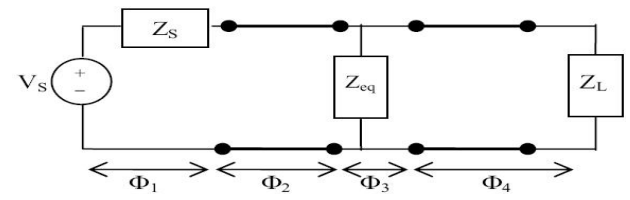

Fig.(4): Partitioned power line network [3].
A power line network of Fig.(3) can be partitioned to four sub-circuits denoted by $\Phi 1, \Phi 2, \Phi 3$ and $\Phi 4$. It can be noted that sub-circuit $\Phi 1$ is a serially connected load; sub-circuits $\Phi 2$ and $\Phi 4$ are power line sections while $\Phi 3$ is load impedance in parallel. Hence, the $\mathrm{ABCD}$ matrix for the transfer function is calculated in [2]:

$$
\begin{aligned}
& \Phi 1=\left(\begin{array}{cc}
1 & Z_{S} \\
0 & 1
\end{array}\right) \\
& \Phi 2=\left(\begin{array}{cc}
\cosh \left(\gamma_{1} d_{1}\right) & Z_{1} \sinh \left(\gamma_{1} d_{1}\right) \\
1 / Z_{1} \sinh \left(\gamma_{1} d_{1}\right) & \cosh \left(\gamma_{1} d_{1}\right)
\end{array}\right) \\
& \Phi 3=\left(\begin{array}{cc}
1 & 0 \\
1 / Z_{\text {eq }} & 1
\end{array}\right) \\
& \Phi 4=\left(\begin{array}{cc}
\cosh \left(\gamma_{2} d_{2}\right) & Z_{2} \sinh \left(\gamma_{2} d_{2}\right) \\
1 / Z_{2} \sinh \left(\gamma_{2} d_{2}\right) & \cosh \left(\gamma_{2} d_{2}\right)
\end{array}\right) \\
&\left(\begin{array}{ll}
A & B \\
C & D
\end{array}\right)=\prod_{i=1}^{3} \phi_{i}=\phi_{1} \phi_{2} \phi_{3} \phi_{4}
\end{aligned}
$$

where: $Z_{1}, \gamma_{1}, Z_{2}$ and $\gamma_{2}$ are the characteristic impedances and propagation constants for the second and fourth subcircuits. Given the value of the ABCD matrix, the transfer function of the power line can be computed easily. However, as the number of bridge taps increases, the complexity involved and the formula for calculating the $\mathrm{ABCD}$ matrix increases in size.

\section{PLC CHANNEL SIMULATION:}

The considered power line communication channel in this paper is the NDEDC outdoor LV power line shown in Fig. (5) which is of the type AL/XLPE with 3 phases and neutral and its cross sectional area is $3 * 150+70$ sq.mm, with sectoral core aluminum conductor and XLPE insulated. This type of cables is used in outdoor installations in damp and wet 
locations, laid direct in the ground (when well protected), in ducts, in trenches and in steel support bracket.

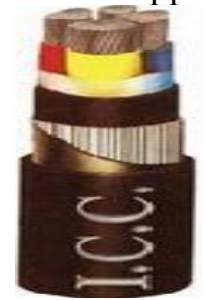

Fig.(5): AL/ XLPE outdoor $L V$ cables of NDEDC.

The simulation results can be obtained by applying the described PLC chain matrix model with different cable lengths, different number of bridge taps with different equivalent impedances and different loading conditions. Two parallel cables, for example power line phase and neutral cables can be modeled as a transmission line. A transmission line can be characterized by its characteristic impedance $Z_{C}$, and its propagation constant $\gamma$. Through the next section the per-unit-length cable parameters are calculated using the catalogue of outdoor cables for NDEDC as described in [5]. Then the characteristic impedance and propagation constant of the cable can be computed using the equations presented in section II.

The MATLAB environment has been used to generate the required scripts to code the channel parameters and equations. For obtaining the study curves a sequence of simulation steps should be done to determine the relation between the magnitude of the transfer function and phase response against the frequency range of PLC channel which is taken from 0 to $30 \mathrm{MHZ}$.

\section{PARAMETERS FOR OUT DOOR LV CABLES:}

As shown in Fig. (6) any transmission line can be represented by knowing the values of $\mathrm{R}, \mathrm{L}, \mathrm{C}$, and $\mathrm{G}$. the value of each parameter can be calculated by using the technical data of LV cable.

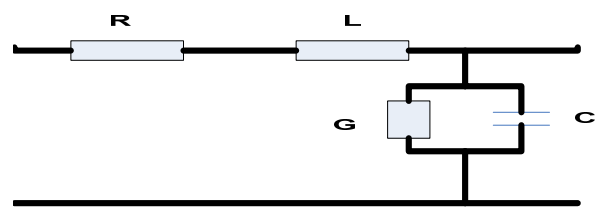

Fig.(6): $R, L, G$, and $C$ power line representation

The following parameter equations are applied for Outdoor LV cables from step down Distribution Transformer (DT) to Customer Pole (CP).

The proposal technique in this study is an investigation in the NDEDC LV grid outdoor cables which is manufactured by the international cables company, all technical data and parameter equations related to cables are described in the manufacturing catalogue [5].

\section{Cable Resistance:}

Considering frequency in MHZ-range the resistance per unit length is dominated by the skin effect and can be approximately expressed by $\mathrm{R}$ as in (7):

$$
R(f)=\sqrt{\frac{\pi \mu_{o}}{\sigma r^{2}} f} \quad[\Omega / \mathrm{m}]
$$

Where:

$\sigma$ : represents the conductivity of Aluminum conductor $\mu \mathrm{o}$ : represents the Permeability of free space $=4 * \pi^{*} 10^{\wedge}-7$

$\mathrm{r}$ : is the cable radius

$\mathrm{f}$ :frequency range (0-30MHZ) 
On The Characterization Of Outdoor Cables As Data Communication Channels. Al-Dosouki, Abdul-Fattah,. Dosouki and Gomaa

Cable Inductance:

$$
\mathrm{L}=K+0.2 \ln \left(\frac{2 S}{d}\right) \quad[\mathrm{mH} / \mathrm{km}]
$$

where: L: Inductance $\mathrm{mH} / \mathrm{Km}$

$\mathrm{K}$ : Constant depends on the conductor's number of wires $=0.0554$

$\mathrm{d}$ :conductors Diameter in $\mathrm{mm}$

$\mathrm{S}$ (in trefoil formation): Axial spacing between cables

\section{Cable Capacitance:}

The value of operating capacitance for cables has been calculated using the following formula.

$$
C=\frac{\varepsilon_{r}}{(18 \ln (D / d))}[\mu f / k m]
$$

\section{Cable Conductance:}

it is frequency dependent value

$G(f)=2 \pi f C \tan \delta \quad[\mathrm{s} / \mathrm{m}]$

where: ${ }^{\varepsilon} r$ : Relative permittivity of insulation material (XLPE)

D: Diameter over insulation (XLPE)

$\mathrm{d}$ : conductor Diameter in $\mathrm{mm}$ $\tan \delta$ : Dielectric loss constant.

\section{LOAD MISMATCH EFFECTS ON PLC CHANNEL MODEL:}

This model is applied to the cables that are used from step down distribution transformer at the kiosk (DT) up to Customer Pole (CP), no bridge tap conditions were used in these power line communication channel model. The cable lengths are kept constant while the effect of varying source impedance at the start of the transmission line model, which is improperly matched with that of the load impedance, is investigated. Fig.(7) illustrates the magnitude of the transfer function of PLC chain matrix model vs. PLC frequency range for the case of constant load impedance ZL of $60 \Omega$ and a varying source impedance $Z s$ $(50,60,100 \Omega)$ for a $2 \mathrm{~m}$ cable length.

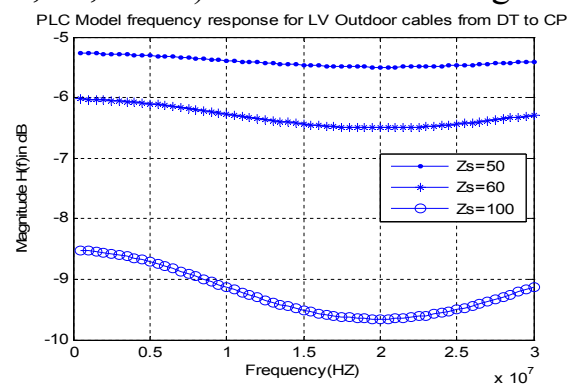

Fig.(7): Transfer function plot frequency response for power line model with $Z L=60 \Omega$ and $Z s=50,60,100 \Omega$ (cable length 2m)

From Fig.(7) it can be deduced that as the input impedance, Zs increases, the attenuation increases provided that the load impedance, ZL is kept constant.

Fig. 8 shows the transfer function phase and magnitude vs. PLC frequency range in the case of constant ZL of $60 \Omega$ and a varying $\mathrm{Zs}(50,60,100 \Omega)$ for a $10 \mathrm{~m}$ cable length.
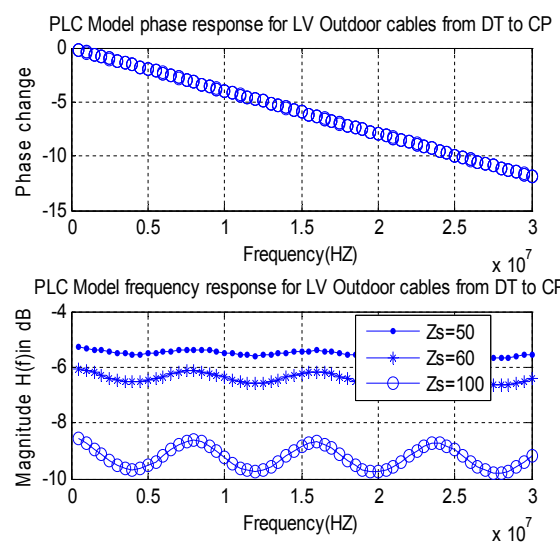

Fig.(8): Transfer Function Plot phase response for Power Line Model with $Z L=60 \Omega$ and $Z s=50,60,100 \Omega$ (cable length $10 \mathrm{~m})$. 
It can be seen from Fig.(8) that the attenuation function is periodically repeated with increasing the cable length, and the phase response of the transfer function is not influenced by the changing of the source impedance.

In the next part the effect of changing load impedance at constant value of source impedance, at similar conditions, is introduced. Fig.(9) shows the magnitude of the transfer function of PLC chain matrix model vs. PLC frequency range for the case of constant $\mathrm{Zs}$ of $60 \Omega$ and varying $\mathrm{ZL}(50,60,100 \Omega)$ for a $2 \mathrm{~m}$ cable length. Fig.10 illustrates the transfer function phase and magnitude vs. PLC frequency range in the case of constant $\mathrm{Zs}$ of $60 \Omega$ and varying $Z L(50,60,100 \Omega)$ for a $10 \mathrm{~m}$ cable length.

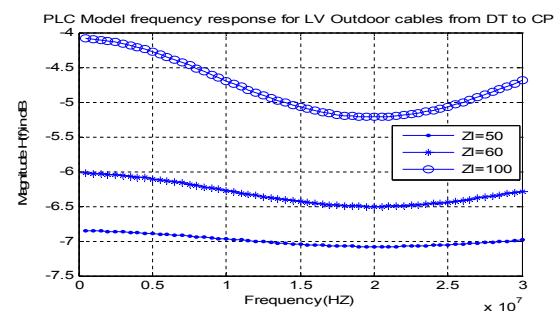

Fig. (9): Transfer function magnitude vs. frequency for PLC model with fixed $\mathrm{Zs}=$ $60 \Omega$ and $Z L=50,60,100 \Omega(L c=2 m)$.

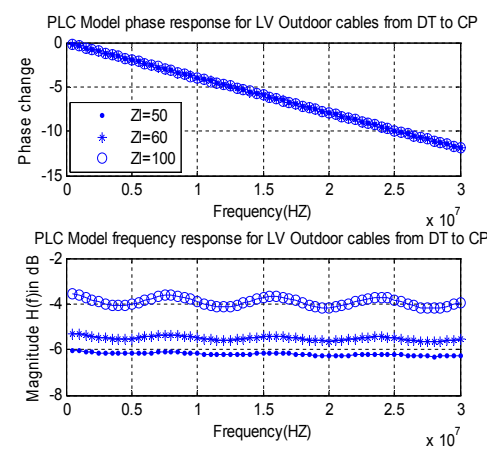

Fig.(10): Transfer function magnitude and phase response vs. frequency for PLC model
It is obviously seen from Figs.(9) and (10) that as the load impedance ZL increases, the attenuation gradually decreases provided that the input impedance $\mathrm{Zs}$ is kept constant. It can also be seen from Figs.(9) and (10) that the attenuation function is periodically repeated with increasing the cable length. The phase response of the transfer function is not influenced by the changing of the load impedance.

\section{LENGTH EFFECTS ON NORMAL PLC CHANNEL:}

In this section the effects of power line lengths on the attenuation of the transmission line are investigated under similar loading conditions, first configuration, discussed here is that of a transmission line model without bridge tap. The second configuration, in the next section, takes the presence of bridge taps inter consideration. Fig.(11) determines the transfer function magnitude against PLC frequency range in the case of fixed loading conditions $(\mathrm{Zs}=50 \Omega$ and $\mathrm{ZL}=60 \Omega$ ) and a varied cable length of $0.1,1,2 \mathrm{~m}$.

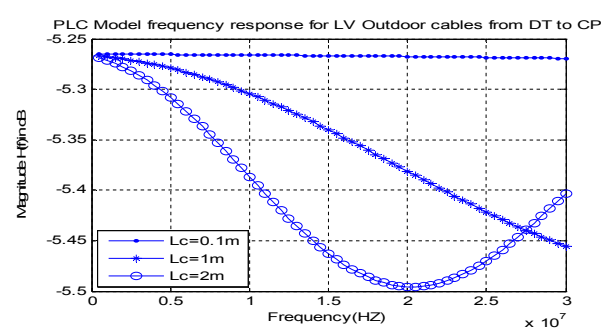

Fig.(11): Transfer function magnitude against frequency for PLC model, case of cable length, $L c=0.1,1,2 \mathrm{~m}$ (No bridge taps), $Z s=50 \Omega, Z L=60 \Omega$. 
On The Characterization Of Outdoor Cables As Data Communication Channels. Al-Dosouki, Abdul-Fattah,. Dosouki and Gomaa

It can be deduced from fig. 11 that as the cable length increases the attenuation gradually increases. Hence, the PLC signal strength will gradually decrease over the distance. Fig.(12) illustrates the transfer function magnitude and phase change against PLC frequency range in the case of fixed loading conditions $(\mathrm{Zs}$ $=50 \Omega$ and $\mathrm{ZL}=60 \Omega$ ) and a varied cable length of $50,100,160 \mathrm{~m}$.
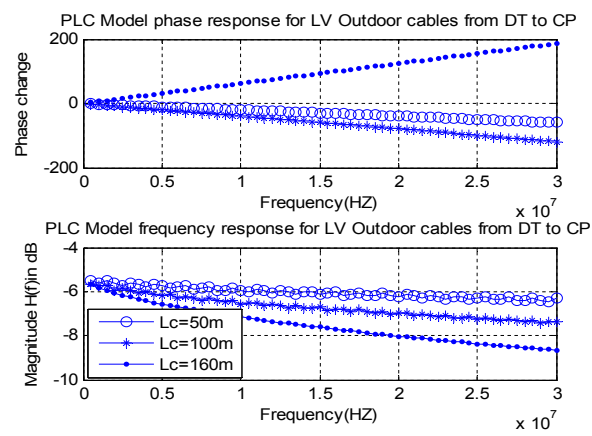

Fig.(12): Transfer function magnitude and phase response vs. frequency for PLC model, case of $L c=$ $50,100,160 \mathrm{~m}$ (No bridge taps), $\mathrm{Zs}=$ $50 \Omega, Z L=60 \Omega$.

It is seen from Fig.(12) that the use of longer lengths of cable gives same conclusion as before that is "as the cable length increases the attenuation gradually increases". In addition Fig.(12) shows a phase reflection, which is happened at a cable length of $160 \mathrm{~m}$, this causes a phase distortion of the PLC transmitted signal. It is required to determine at which portion of the cable the phase distortion is exactly happened. This can be deduced by running MATLAB program with decreasing the cable length from $160 \mathrm{~m}$ till the length at which the phase distortion is happened. Fig.(13) illustrates the transfer function phase and magnitude vs. PLC frequency range in the case of fixed loading conditions $(\mathrm{Zs}=50 \Omega$ and $\mathrm{ZL}=60 \Omega$ ) and a varied cable length of $158,159 \mathrm{~m}$.

It can be seen from Fig.(13) that the phase distortion is exactly happened at cable length of $159 \mathrm{~m}$ with no bridge taps on the cable. It can be concluded that the PLC signal has to be transmitted at maximum cable length of $158 \mathrm{~m}$ with the given loading conditions; otherwise additional complicated communication tools should be added to regenerate and amplify the signal.

Fig.(14) describes the transfer function phase and magnitude vs. cable length in the case of fixed loading conditions $(\mathrm{Zs}=50 \Omega$ and $\mathrm{ZL}=60 \Omega$ ) and a varied PLC frequency values (15 MHZ, 20 MHZ, 25 MHZ, 30 MHZ).

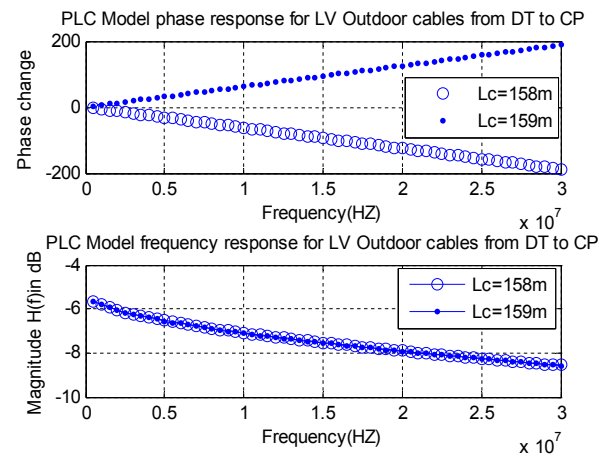

Fig.(13): Transfer function magnitude and phase response against frequency for PLC Model with $L c=158,159 \mathrm{~m}$ (No bridge taps) 


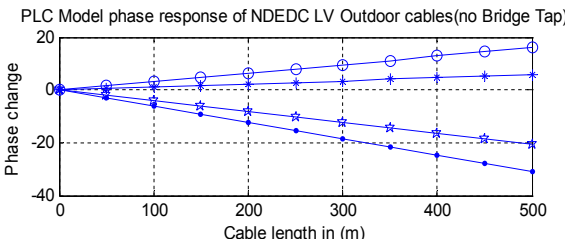

PLC Model frequency response of NDEDC LV Outdoor cables(no Bridge Tap)

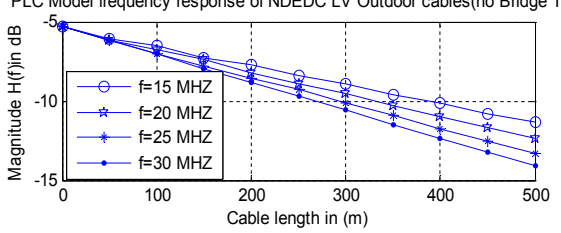

Fig.(14): Transfer function magnitude and phase response against cable length for PLC Model with $L c=$ 0 $\sim 500 \mathrm{~m}$ (no bridge taps), Zs $=50 \Omega$, $Z L=60 \Omega$.

Fig.(14) also summarizes the effects of cable length of $500 \mathrm{~m}$ on the PLC channel attenuation and phase response. It is shown in the figure that the maximum value of attenuation is happened at frequency of $30 \mathrm{MHZ}$ and cable length of $500 \mathrm{~m}$ for the given loading conditions, which means that the signal attenuation 'of typical power cables' increases with cable length and frequency. It can also be seen from Fig.(14) that the phase response of the transfer function is influenced by the varying of the cable length.

\section{PRESENCE OF BRIDGE TAP EFFECTS ON PLC CHANNEL MODEL}

This section investigates the effect of different cable lengths with one bridge tap on the PLC signal in outdoor LV power line channel model (phase and frequency response) under similar loading conditions. This bridge tap has different lengths and different load impedances.
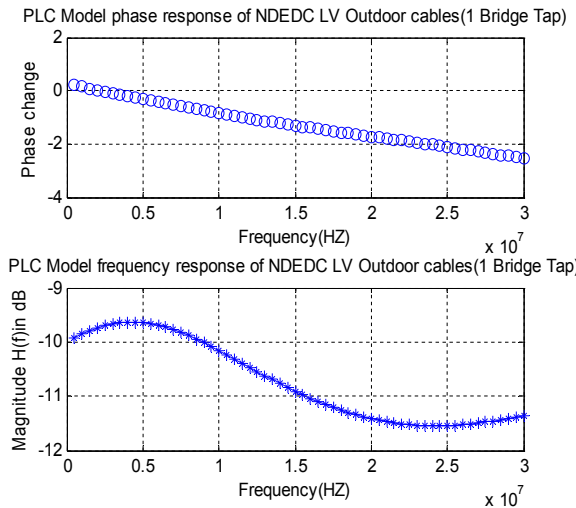

Fig.(15): Transfer function phase and magnitude against frequency for PLC model in case of $\mathrm{Lc}=\mathbf{2 m}, \mathrm{Br}=1 \mathrm{~m}, \mathrm{Zbt}$ $=50+\mathrm{j} 100 \Omega, Z s=50 \Omega$, and $Z L=60 \Omega$.

Fig.(15) shows the transfer function phase and magnitude vs. PLC frequency rang in the case of constant loading conditions $\left(\mathrm{ZL}=60 \Omega, \mathrm{Zs}_{\mathrm{s}}=50 \Omega\right)$, cable length of $2 \mathrm{~m}$, bridge tap length of $1 \mathrm{~m}$, and bridge tape load impedance of $50+\mathrm{j} 100 \Omega$.

It can be seen from Fig.(15) that the PLC attenuation value is low at low frequencies and is high at high frequencies. It can be seen also from Fig.(15) that the phase response of the transfer function is not influenced by the adding of one bridge tap with the listed conditions.

It can be seen from Fig.(16) that the PLC attenuation value is low at frequencies below 20MHZ and its value is increased gradually at higher frequencies, it can be deduced that a longer bridge length on the communication line will significantly increase the attenuation when compared to the scenarios without bridge taps. 
On The Characterization Of Outdoor Cables As Data Communication Channels. Al-Dosouki, Abdul-Fattah,. Dosouki and Gomaa
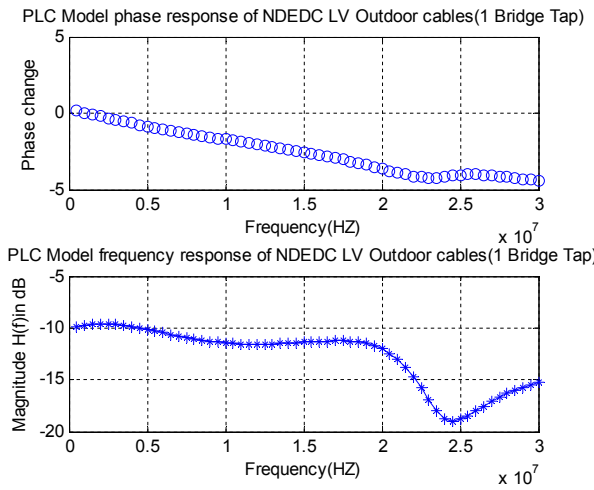

Fig.(16): Transfer function plot phase and frequency response for PLC Model with $\mathrm{Lc}=4 \mathrm{~m}$ and $\mathrm{Br}=2 \mathrm{~m}$ with $Z b t=50+j 100 \Omega, Z s=50 \Omega, Z L=60 \Omega$.

It can be seen also from Fig.(16) that the phase response of the transfer function is influenced by the adding of one bridge tap with the listed conditions at frequencies between 20MHZ and $25 \mathrm{MHZ}$.
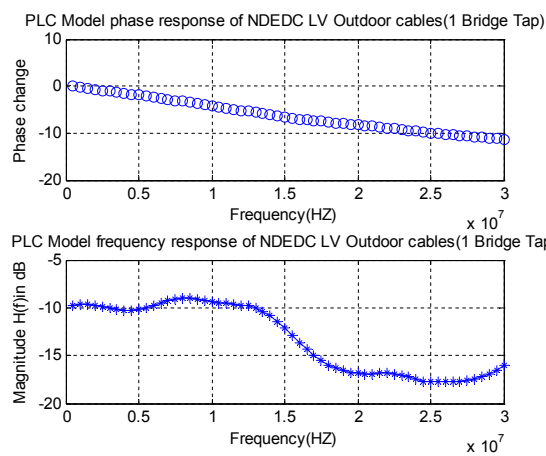

Fig.(17): Transfer function plot phase and frequency response for PLC model with $L c=10 \mathrm{~m}$ and $B r=2 \mathrm{~m}$ with $Z b t=50+j 100 \Omega, Z s=50 \Omega, Z L=60 \Omega$.

It can be seen from Fig.(17) that the PLC attenuation value is low at frequencies below 13MHZ, and its value is high at higher frequencies. It can be seen also from Fig.(17) that the phase response of the transfer function is not influenced by the adding of one bridge tap with the listed conditions.
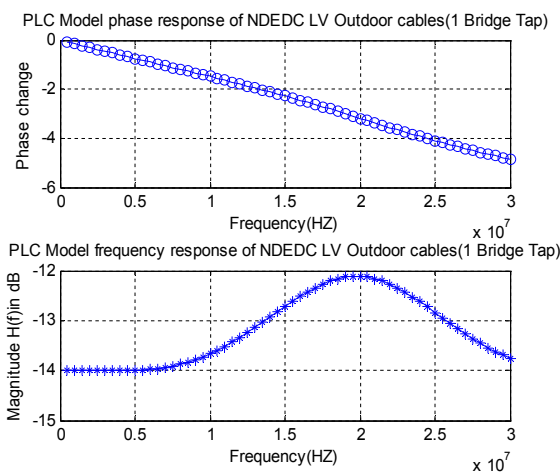

Fig.(18): Transfer function plot for power line model with cable length $4 \mathrm{~m}$ and bridge tap length $2 \mathrm{~m}$ with branch impedance $50 \Omega, Z_{s}=50 \Omega$, $\mathbf{Z L}=\mathbf{5 0 \Omega}$.

According to Fig.(18) the using of matched loading conditions with real value of bridge tap load impedance enhancing the performance of PLC channel only at high frequency at same cable length and bridge length, while at low frequencies the value of attenuation is increased (compared with Fig.(16). This is suitable for transmitting the PLC signal as it requires high range of frequencies to be transmitted.

From this section, it can be deduced that a longer bridge length on the communication line will significantly increase the attenuation when compared to the scenarios without bridge taps. This can be justified with the fact that bridge taps are acting as interference and the longer the bridge tap length, the stronger the effect of the interference. Hence, 
longer bridge taps will weaken the signal on the communication line.

Fig.(19) describes the transfer function phase and magnitude against cable length for PLC model, in case of cable length $0: 500 \mathrm{~m}$, bridge tap length of $2 \mathrm{~m}$, bridge tape load impedance of $50+\mathrm{j} 100$ $\Omega$ and load conditions of $\mathrm{Zs}=50 \Omega, \mathrm{ZL}$ $=60 \Omega$, at different frequency values of (20 MHZ, 25 MHZ, $30 \mathrm{MHZ}$ ).
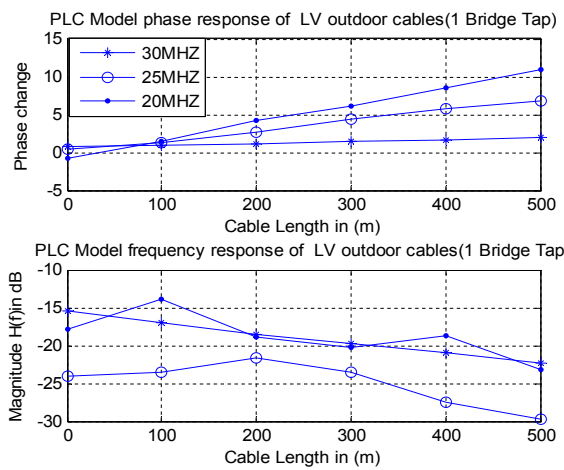

Fig.(19): Transfer function phase and magnitude vs. cable length for PLC model, in case of $L c=0: 500 \mathrm{~m}$ and $\mathrm{Br}$ $=\mathbf{2 m}$ with $\mathrm{Zbt}=\mathbf{5 0}+\mathbf{j 1 0 0} \Omega, \mathrm{Zs}=\mathbf{5 0 \Omega}$,

$$
\mathrm{ZL}=\mathbf{6 0 \Omega} \text {. }
$$

As shown in Fig.(19) it summarizes the effects of cable length on the PLC channel attenuation, it can be seen that the maximum value of attenuation is $-30 \mathrm{~dB}$ which is happened at frequency of 25 MHZ and cable length of $500 \mathrm{~m}$ at the listed bridge tap and load conditions.

Since the quality of the transmission is highly influenced by the characteristics of the channel itself. It can be deduced from Fig.(19) that for the considered PLC channel the attenuation depends on the characteristics of the cables (length, per-unit-length parameters, frequency dependence, and bridge tap length with load impedance) at fixed load conditions.

\section{BRIDGE TAP CONDITIONS EFFECT ON PLC CHANNEL MODEL:}

This section discusses the sectioned power line cable with different bridge taps conditions. The partitioned cable includes a PLC channel with single bridge tap, three bridge taps and five bridge taps. The load conditions for all models are kept constant while the cable length and bridge tap loads and lengths are varied. Fig.(20).a shows the transfer function magnitude and phase response vs. PLC frequency rang in the case of load match conditions of $\mathrm{ZL}=60 \Omega$, $\mathrm{Zs}=50 \Omega$, cable length of $10 \mathrm{~m}$, with one bridge tap of $2 \mathrm{~m}$ length and load impedance of $200 \Omega$.
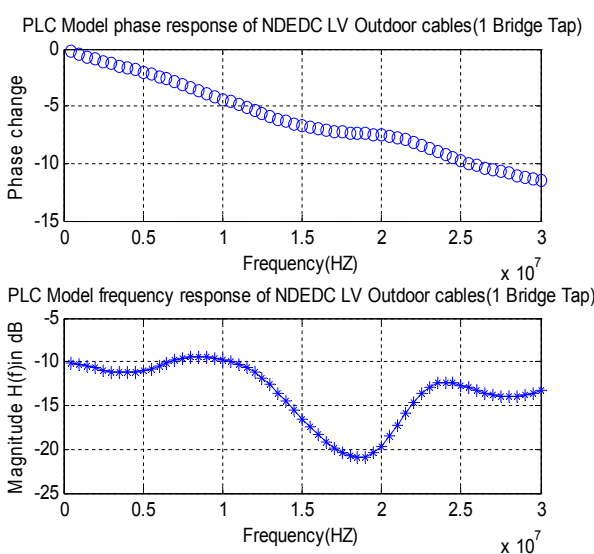

Fig.(20).a: Transfer function magnitude and phase response against frequency for PLC model 
On The Characterization Of Outdoor Cables As Data Communication Channels. Al-Dosouki, Abdul-Fattah,. Dosouki and Gomaa

It can be seen from Fig.(20).a that the PLC channel attenuation values are low at frequencies below 13MHZ, and are high at higher frequencies, it can be also seen from Fig.(20).a that occurrence of phase distortion is happened at frequencies within 20MHZ.

It can be seen from Fig.(20).b that the PLC channel attenuation is low at frequencies below $8 \mathrm{MHZ}$, then the attenuation values is increased to maximum value at frequency of $20 \mathrm{MHZ}$ then the curve of attenuation function is decreased gradually at higher frequencies . It can be seen also from Fig.(20).b that the phase response of the transfer function is influenced in the frequency range from $17 \mathrm{MHZ}$ to $25 \mathrm{MHZ}$, it can be deduced that for a partitioned cable with 3 bridge taps of listed conditions the best ranges of frequencies to use for PLC signal is below $8 \mathrm{MHZ}$ for low frequencies ranges and upper $25 \mathrm{MHZ}$ for high frequencies ranges.

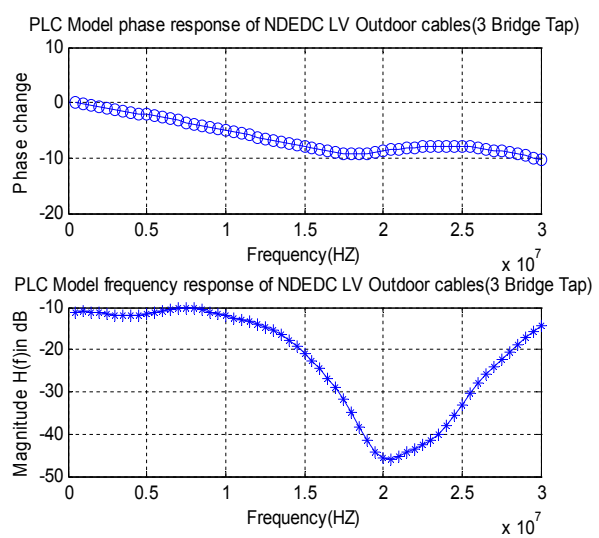

Fig.(20).b: Transfer function magnitude and phase response for PLC model
Fig.(20).c shows the transfer function Plot for Power Line Model with total cable length $10 \mathrm{~m}$ and 5 bridge taps of impedances $50+\mathrm{j} 100,150,450,100+\mathrm{j} 50$ and $200 \Omega$ and bridge tap lengths 2,5 , 1,2 and $1 \mathrm{~m}, \mathrm{Zs}=50 \Omega$ and $\mathrm{ZL}=60 \Omega$.

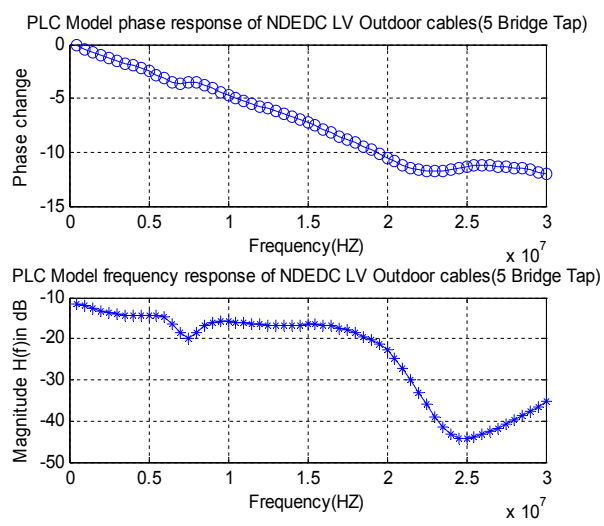

Fig.(20).c: Transfer function magnitude and phase response for PLC model

From Figures (20).a to (20).c it can be deduced that as the number of bridge taps increases, the attenuation significantly and rapidly increases. Multiple bridge taps with varying length means multiple interference having varying strengths. Out of all cases, the scenario where there is multiple bridge taps have the most pronounced effect on the attenuation showing that the number of bridge taps is a strong determinant of signal attenuation.

Fig.(17) shows the effect of cable dividing before bridge taps, through bridge taps, and after bridge taps. 


\section{OUTDOOR PLC MODEL WITH PARTITIONED CABLE:}

This section investigates the effects of partitioning the power cable with different cable lengths before bridge tap, through bridge tap, and after bridge tap on the considered PLC channel model. This investigation depends on the use of five bridge taps with varied loads and lengths under similar loading conditions.

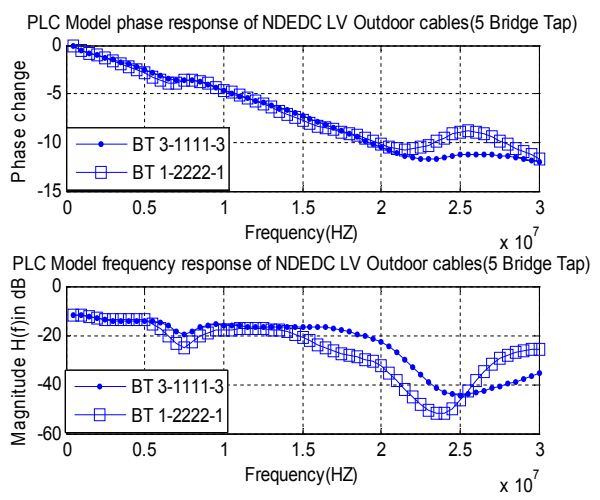

Fig.(21): Transfer function plot for power line model with total cable length 10m (divided to 1-2-2-2-2-1m and 3-1-1-1-1-3) and 5 bridge taps

Fig.(21) describes the transfer function magnitude and phase response vs. PLC frequency rang in the case of fixed load conditions of $\mathrm{ZL}=60 \Omega, \mathrm{Zs}=50 \Omega$, tow cables of $10 \mathrm{~m}$ length, with five bridge taps of lengths $2,5,1,2$, and $1 \mathrm{~m}$ respectively, and each bridge tap has load impedance of $50+\mathrm{j} 100 \Omega, 150 \Omega, 450 \Omega$, $100+\mathrm{j} 50 \Omega$, and $200 \Omega$ respectively. The first cable is divided to 3 meters before first bridge tap then 1 meter between each bridge tap and the other, and then it is ended with 3 meters after the fifth bridge tap, it is denoted on the curve with (BT 3-1111-3). The second cable is divided to 1 meter before first bridge tap then 2 meters between each bridge tap and the other, and then it is ended with 1 meter after the fifth bridge tap, it is denoted on the curve with (BT 1-2222-1). As shown in Fig.(21) the attenuation value in the first cable is lower than its value in the second one especially at high frequencies. It can also be seen that the phase response of the transfer function is more influenced by the increasing of the cable length between each bridge tap and the other as shown on the phase change of the second cable curve.

It can be concluded from Fig.(21) that the dividing of the cable affects the signal attenuation and causes phase distortion, as if the cable length increases through bridge taps the attenuation gradually increases, including signal interferences and distortions especially at high frequencies.

\section{CONCLUSION}

This paper introduces new results for the outdoor LV power line cables which are used in the Egyptian North Delta Electricity Distribution Company (NDEDC). The channel consists of four core cable with reduced neutral.

Based on the chain matrix theory, the transfer functions of a sampled and branched power line channel have been obtained. The function model of the considered PLC is simulated using MATLAB, and the effect of using different loading conditions, cable lengths and number of bridge taps on the efficiency of the communication channel is investigated. Simulation results indicate that there are significant attenuations 
On The Characterization Of Outdoor Cables As Data Communication Channels. Al-Dosouki, Abdul-Fattah,. Dosouki and Gomaa

and distortions as the number of branches, cable length, and load mismatch are increased. From phase response curves it is observed that multibranched PLC channel has phase distortion at very high frequency $22 \sim 30 \mathrm{MHZ}$ so it is recommended to transmit data signal up to $21 \mathrm{MHZ}$ at this type of PLC channels. It is also concluded that NDEDC LV Outdoor cables (without bridge taps) have phase distortion at cable length more than 158 meters for that it is recommended to use cable within this length, otherwise it is required a complicated communication system to regenerate or amplify the data signal. In other word, the dividing of the cable affects the signal attenuation and causes phase distortion, as if the cable length increases through bridge taps the attenuation gradually increases, including signal interferences and distortions especially at high frequencies.

However this study acts as a guide in the applying of the PLC technology in a developing country like Egypt.

\section{REFERENCES}

1- Xin Ding and Julian Meng, June 10 14, 2007, "Characterization And Modeling Of Indoor Power-Line Com-Munication Channels". $2^{\text {nd }} \mathrm{Ca}$ nadian Solar Buildings Conference Calgary.

2- Sheroz Khan, A. F. Salami, W. A. Lawal, AHM Zahirul Alam, Shihab Abdel Hameed, and M. J. E. Salami, DECEMBER 2008, "Characterization of Indoor Power lines As Data Communication Channels Experimental Details and Results". PROCEEDINGS
OF WORLD ACADEMY OF SCIENCE, ENGINEERING AND TECHNOLOGY VOLUME 36 ,ISSN 20703740 ,

3- J. Anatory, N. H. Mvungi, and M. M. Kissaka, WINTER-SPRING 2004, "Analysis of Power line Ch-annel Model for Communication from Primary Substation Node to End-Users" IRANIAN JOURNAL OF ELECTRICAL AND COMPUTER ENGINEERING, VOL. 3, NO. 1.

4- Anatory1, Nelson Theethayi2, Rajeev Thottappillil2, M.M. Kissaka1, N.H.Mvungi1, 2006 ,"The Effects Of Interconnections And Bran-Ched Network In The Broadband Powerline Communications" Faculty of Electrical and Computer Systems Engineering, University of Dar el Salaam, P.o.Box 35131, DSM, Tanzania.

5-INTERNATIONAL CABLES COMPANY, http://www.intlcables.com.

6- T. Esmailian, F. R. Kschischang, and P. G. Gulak, 2002," An In-building Power Line Channel Simulator", University of Toronto ,Department of Electrical and Computer Engineering, Canada. 